\title{
PILARES DA EDUCAÇÃO LASSALISTA COMO PERSPECTIVA PARA UMA EDUCAÇÃO DE QUALIDADE*
}

Pillars of Lassallian Education as a Perspective for Quality Education

Ana Marli Hoernig **

\section{Resenha de:}

MENEGAT, Jardelino. O ideário educativo lassalista e os marcos regulatórios de educação: pilares para uma educação de qualidade. Tese (Doutorado em Educação). Canoas: Universidade La Salle, 2016.

A tese apresenta uma distinta estrutura e caracteriza-se por apresentar grande clareza em sua abordagem. Quanto à organização do conteúdo, a obra encontra-se disposta em oito capítulos, que se encontram subdivididos em até, no máximo, quatro sessões. Após o desenvolvimento dos capítulos da tese, seguem as referências e apêndices.

O autor apresenta a sua obra de forma detalhada e compreensiva, tornando a tese um marco orientador de ações práticas educacionais. O fato de viver em seu cotidiano como Irmão lassalista, vinculado ao Instituto dos Irmãos das Escolas Cristãs e atuar como gestor educacional das instituições lassalistas, certamente contribui para que isto ocorra. Os principais conceitos abordados evidenciam a dimensão central da investigação, e são apresentados e discutidos ao longo da obra. A tese de Jardelino Menegat está assim formulada: O Ideário Educativo Lassalista contempla o que preconizam os Marcos Regulatórios da Educação relativos aos elementos que caracterizam a educação de qualidade, demonstrando que, em termos educacionais, a educação lassalista está na vanguarda.

No primeiro capítulo, introduz o tema da pesquisa, mencionando que o Ideário Educativo Lassalista foi se revitalizando ao longo dos mais de trezentos anos da história lassaliana, situando os Marcos Regulatórios da Educação como dispositivos que regulam a educação para transformá-la em educação de qualidade e passa a esquadrinhar este conceito ao longo da tese. Para definir "educação de qualidade", Menegat parte do que preconizam as Diretrizes Curriculares Nacionais da Educação Básica ${ }^{1}$ até chegar às perspectivas relacionadas ao tema da tese, de forma a alicerçar a prática educativa nos pilares para esta educação de qualidade, apresentados no capítulo seis.

* Enviado em: 05.07.2019. Aceito em: 30.03.2020.

** Doutoranda em Educação na Universidade La Salle, Canoas, RS. Mestrado no Ensino de Ciências e Matemática (ULBRA). Graduada em Ciências e Biologia (PUCRS). E-mail: anamarlih7@gmail.com

1 Brasil. Ministério da Educação. Diretrizes Curriculares Nacionais para Educação Básica. Brasília: MEC, SEB, DICEI, 2013. Disponível em: http://portal.mec.gov.br/docman/julho-2013-pdf/13677-diretrizes-educacao-basica-2013pdf/file

Protestantismo em Revista | São Leopoldo | v. 45, n. 02 | p. 181-185| Jul./dez. 2019

Disponível em: <http://periodicos.est.edu.br/index.php/nepp> 
No segundo capítulo apresenta a pesquisa e os procedimentos metodológicos, descrevendo as justificativas pessoal-profissional, acadêmico-científica e social que são relevantes à pesquisa, caracterizando o estudo e situando o percurso percorrido para efetivar sua investigação. O terceiro capítulo contextualiza o Instituto dos Irmãos das Escolas Cristãs, sua origem, seus princípios fundacionais. Situa também a Rede La Salle no âmbito da América Latina, Caribe e Chile.

O Ideário Educativo Lassalista constitui-se do conjunto de ideias, aspirações, objetivos e programas de ação de uma organização, a organização educacional, no caso específico da tese em questão. O quarto capítulo realiza uma incursão no rico Ideário, elegendo os documentos analíticos, no contexto nacional e internacional, que constituem o corpus investigativo do estudo, de onde emergiram os princípios que caracterizam a educação de qualidade.

Os Marcos Regulatórios de Educação compreendem o conjunto de dispositivos, leis e normatizações que regulam o funcionamento de uma organização. O quinto capítulo retoma os principais dispositivos legais que abordam a educação de qualidade nos contextos internacional e nacional, destacando os que constituem o corpus investigativo, onde foram buscados os princípios que caracterizam a educação, compreendida como um direito dentro de um conjunto de outros direitos humanos.

No sexto capítulo são estabelecidos os Pilares da Educação Lassalista para uma educação de qualidade. São construídos a partir dos princípios definidos pelas aproximações e distanciamentos entre o ideário educativo lassalista e os marcos regulatórios de educação. Entre os princípios de educação de qualidade definidos, citamos um, a partir do ideário educativo lassalista, qual seja: educação a partir da promoção do respeito aos direitos humanos, especialmente da infância e juventude, e citamos outro a partir dos marcos regulatórios - promoção dos princípios do respeito aos direitos humanos, especialmente das crianças em situação de vulnerabilidade social. Estes dois princípios evidenciam a aproximação entre o ideário educativo lassalista e os marcos regulatórios da educação.

Da incursão analítica ao corpus investigativo resultou a identificação de cinco Pilares da Educação Lassalista, que são: revitalizar o Identidade e a Missão Educativa; promover os direitos humanos e trabalhar pela erradicação de todas as formas de discriminação; efetivar a prática educativa de acolhimento, do cuidado e de uma educação que prepara para a vida; consolidar redes de cooperação, constituindo comunidades educadoras, e, gerenciar, monitorar e aprimorar os processos e as práticas de gestão.

O sétimo capítulo discorre sobre desafios, esperanças e perspectivas para a consolidação dos Pilares da Educação Lassalista. Isto é feito revisitando a tese e explicitando os elementos que sinalizam para sua confirmação. As Considerações finais retomam os principais achados do estudo e suas limitações com algumas sugestões para futuras investigações.

A obra apresenta diversas contribuições para pesquisa em educação. Como acolher as sugestões de pesquisa propostas pelo autor nas considerações finais, bem como outras possibilidades que se delineiam nas linhas e entrelinhas do texto. $O$ autor, pelos achados do estudo, sinaliza para a confirmação da tese postulada e então entende que isto poderá contribuir para reflexões acerca da educação de qualidade em instituições de ensino, mesmo que não sejam necessariamente lassalistas. Desta maneira entendemos que a tese permite o acesso à pesquisa para educadores/pesquisadores em geral. Além destas possíveis contribuições que a obra permite, pode-se utilizá-la como modelo e referência de excelência para elaboração de outras trabalhos e pesquisas, dado sua adequada estruturação, sua fundamentação teórica coerente com a metodologia adotada, sua inclinação epistemológica e a relevância indiscutível do tema abordado.

Protestantismo em Revista | São Leopoldo | v. 45, n. 02 | p. 181-185| Jul./dez. 2019 
O referencial teórico que embasa a tese é extenso, constituído pelos documentos lassalistas e pelos marcos regulatórios da educação (escolhidos pelo autor e listados no capítulo dois), por teses e dissertações que tem como centralidade investigativa a educação lassalista. Para a análise das temáticas extraídas do material selecionado o autor utilizou a técnica de análise de conteúdo proposta por Bardin, a qual configura-se num conjunto de técnicas que possibilita a realização de inferências, por meio de procedimentos sistemáticos de descrição do conteúdo.

O autor da tese não explicita a epistemologia adotada, entretanto afirma que toda escolha teórica está alicerçada em paradigmas que temos sobre os modos de conceber e atuar na educação. Para o autor, a posição epistemológica adotada em uma tese é declarada ao escolher um conjunto de autores em detrimento de outros. $\mathrm{O}$ autor da tese menciona que o cenário de incertezas que vivemos no presente momento da história é resultado da exaustão do paradigma vigente, bem como do surgimento de um novo paradigma. Cita o sociólogo Boaventura de Souza Santos², o qual afirma que para saber viver, faz-se necessário uma forma de conhecimento compreensiva que una a todos e, para isto, diz Menegat, as instituições educativas podem contribuir. Os pilares educacionais lassalistas poderão contribuir como bases fundantes para a educação que se almeja, de forma que se encontre no bojo do novo paradigma que vem se delineando.

Desta maneira, depreendemos a partir da leitura da obra que o autor, de forma implícita, se inspira na concepção epistemológica de Thomas Kuhn ${ }^{3}$, no momento em que evoca Boaventura e a discussão sobre paradigmas, porém aqui trazida para o âmbito da discussão de paradigmas da educação. Analisando a tese como um todo podemos entender que na pedagogia lassaliana coexistem mais de uma vertente epistemológica, e que Menegat dialoga com estas vertentes. A perspectiva de prospectar os pilares da educação estabelecidos para a própria educação lassalista e, para além dela, evidencia este entendimento. Contudo, nesta breve análise da tese de Jardelino Menegat, temos como relevante o embasamento teórico em escritos de autores lassalistas como Edgar Hengemüle ${ }^{4}$, ficando notório, portanto, a filosofia/pedagogia de João Batista de La Salle como a epistemologia que perpassa sua tese.

Menegat faz uma pesquisa descritiva pois analisa fatos e fenômenos. Sua pesquisa é documental e, então, a partir de documentos, descreve e compara tendências, diferenças e outras características da realidade, que constituem o paradigma vigente. Considerando as incertezas que abalam este paradigma, o autor, a partir das aproximações e distanciamentos entre os princípios dos documentos analisados - ideário educativo lassalista e marcos regulatórios da educação - evoca os pilares da educação lassalista, prospectando-os para o novo paradigma que se anuncia. Tais pilares da educação pretenderão dar sua contribuição no sentido de alicerçar este novo paradigma no contexto educacional.

A pretensão do autor ao fazer a incursão no corpus investigativo da pesquisa, a partir das aproximações e distanciamentos do ideário educativo lassalista e dos marcos regulatórios da educação, em nível nacional e internacional, ou em ambos, de fazer emergir os Pilares da Educação Lassalista, é sem dúvida a confirmação da tese postulada pelo autor. Os achados do estudo confirmam as perspectivas para uma educação, que poderão, segundo o autor, contribuir para que esta seja um direito de todos, que pode ocorrer em instituições educativas de educação básica ou superior, públicas ou privadas, confessionais ou laicas.

2 SANTOS, Boaventura de Souza. Um discurso sobre as ciências. 5. Ed. São Paulo: Cortez, 2008.

3 KUHN, Thomas. A estrutura das revoluções científicas. São Paulo: Perspectiva, 5 ed. 1998.

HENGEMÜLE, Edgard. Educação Lassalista: que educação. Canoas: Salles, 2007.

Protestantismo em Revista | São Leopoldo | v. 45, n. 02 | p. 181-185| Jul./dez. 2019

Disponível em: <http://periodicos.est.edu.br/index.php/nepp> 


\section{Referências}

Brasil. Ministério da Educação. Diretrizes Curriculares Nacionais para Educação Básica. Brasília: MEC, SEB, DICEI, 2013. Disponível em: http://portal.mec.gov.br/docman/julho-2013-pdf/13677diretrizes-educacao-basica-2013-pdf/file. Acesso em: 03 Jul. 2019.

HENGEMÜLE, Edgard. Educação Lassalista: que educação. Canoas: Salles, 2007.

KUHN, Thomas. A estrutura das revoluções cientificas. São Paulo: Perspectiva, 5 ed. 1998.

SANTOS, Boaventura de Souza. Um discurso sobre as ciências. 5. Ed. São Paulo: Cortez, 2008. 


\section{Referências}

Brasil. Ministério da Educação. Diretrizes Curriculares Nacionais para Educação Básica. Brasília: MEC, SEB, DICEI, 2013. Disponível em: http://portal.mec.gov.br/docman/julho-2013-pdf/13677diretrizes-educacao-basica-2013-pdf/file

HENGEMÜLE, Edgard. Educação Lassalista: que educação. Canoas: Salles, 2007.

KUHN, Thomas. A estrutura das revoluções científicas. São Paulo: Perspectiva, 5 ed. 1998.

SANTOS, Boaventura de Souza. Um discurso sobre as ciências. 5. ed. São Paulo: Cortez, 2008. 